\title{
ARTIGOS
}

\section{AS CICATRIZES DA LUTA PELA TERRA NA FRONTEIRA AMAZÔNICA ${ }^{1}$}

Rafael Benevides de Sousa ${ }^{2}$

Universidade Federal do Sul e Sudeste do Pará

\section{Enviado em 28 set. 2020 | Aceito em 11 mai. 2021}

Resumo: Este artigo é fruto de um projeto de pesquisa e extensão desenvolvido junto a Comissão Pastoral da Terra (CPT), com sede em Xinguara, sul do Pará. O objetivo aqui proposto é compreender a geografia dos conflitos agrários na fronteira amazônica a partir do acervo arquivístico Frei Henri des Roziers, da CPT. Essa base documental serviu para entendermos metodologicamente os elementos que têm constituído os conflitos agrários nessa parte do Brasil. Como resultado, destaca-se a expansão dos latifúndios grilados e especulativos como causadores dos principais conflitos no campo, o que acontece concomitantemente as ações de violência e mortes de camponeses, sindicalistas, religiosos, advogados e lideranças. Vislumbra-se, assim, com esse artigo, apresentar a natureza dos conflitos agrários que são grafadas como cicatrizes da luta pela terra na fronteira amazônica.

Palavras-chave: Conflitos agrários, violência, camponeses, luta pela terra, fronteira amazônica.

\section{THE SCARS OF THE STRUGGLE FOR LAND IN THE AMAZONIAN FRONTIER}

Abstract: This article is the result of a research and extension project developed jointly with the Pastoral Land Commission (Comissão Pastoral da Terra - CPT), based in Xinguara, in the South of Pará. The proposed objective here is to understand the geography of the agrarian conflicts on the Amazonian frontier based on Frei Henri des Roziers' archival collection, from CPT. This documentary base served to understand in methodological terms the elements that have constituted the agrarian conflicts in this part of Brazil. As a result, the expansion of grabbed and speculative latifundia stands out as the cause of the main conflicts in the countryside, which happens simultaneously with the actions of violence and the deaths of peasants, unionists, religious figures, lawyers and leaders. Thus, this article aims to present the nature of agrarian conflicts that are graphed as scars of the struggle for land on the Amazonian frontier.

Keywords: Agrarian conflicts, violence, peasants, struggle for land, Amazonian frontier.

\section{LAS CICATRICES DE LA LUCHA POR LA TIERRA EN LA FRONTERA AMAZÓNICA}

Resumen: Este artículo es el resultado de un proyecto de investigación y extensión desarrollado con la Comisión Pastoral de la Tierra (Comissão Pastoral de Terra - CPT), con sede en Xinguara, al sur de Pará. El objetivo aquí propuesto es comprender la geografía de los conflictos agrarios en la frontera amazónica desde a partir de la colección de archivos de Frei Henri des Roziers, del CPT. Esta base documental sirvió para comprender metodológicamente los elementos que han constituido los conflictos agrarios en esta parte de Brasil. Como resultado, se destaca la expansión de los latifundios ilegales y especulativos como la causa de los principales conflictos en el campo, lo que ocurre concomitantemente con acciones de violencia y muerte de campesinos, sindicalistas, religiosos, abogados y dirigentes. Así, este artículo tiene como objetivo presentar la naturaleza de los conflictos agrarios que se escriben como cicatrices de la lucha por la tierra en la frontera amazónica.

Palabras clave: Conflictos agrarios, violencia, campesinos, lucha por la tierra, frontera amazónica.

1 Este artigo é o resultado do projeto de pesquisa "Territorialização Camponesa no Sul e Sudeste do Pará, financiado pela Fundação Amazônia de Amparo a Estudos e Pesquisa (FAPESPA) e do projeto de extensão "Os mártires da terra: espaço e memória dos conflitos agrários a partir do Acervo da Pastoral da terra - Xinguara/PA, financiado pela Pró-reitoria de extensão e assuntos estudantis da Universidade Federal do Sul e Sudeste do Pará (PROEX-Unifesspa).

2. Doutor em Geografia. Professor do Curso de Graduação em Geografia da Universidade Federal do Sul e Sudeste do Pará, Campus Xinguara. ORCID: https://orcid.org/0000-0001-6084-2486. E-mail: rafael.benevides@unifesspa.edu.br 
Introdução

\begin{abstract}
Maior e mais conhecido massacre registrado na luta pela terra, o caso de Eldorado dos Carajás se refere ao assassinato de dezenove sem-terras mortos pela Polícia Militar do Estado do Pará, no dia 17 de abril de 1996. O massacre ocorreu quando 1.500 sem-terra acampados na região realizavam uma marcha obstruindo a BR-155 em protesto contra a demora da reforma agrária no local. Sob o aval do secretário de segurança pública estadual, o coronel responsável pela operação empreendeu atos de repressão e violência que culminaram nas mortes a queima roupa e por cortes.

Apesar da grande repercussão nacional, a apuração não prendeu ou identificou os policiais que atiraram. Propina teria sido paga por fazendeiros da região, [...], para que os policiais matassem as lideranças sem-terra. (CPTNACIONALMASSACRES NO CAMPO)
\end{abstract}

A morte de 19 sem-terras no conhecido massacre de Eldorado dos Carajás foi apenas mais um episódio dos inúmeros conflitos com violência registrados no campo brasileiro e, de forma particular, na fronteira amazônica. Essa problemática tem sido uma constante, colocando na ordem do dia os embates emergidos por uma questão agrária que tem como característica um campo em disputa, materializado em fronts de lutas sociais pelo direito à terra e à água, pelo reconhecimento dos territórios étnicos e tradicionais, pelo combate ao trabalho análogo à escravidão e de defesa da vida.

Os dados analisados e divulgados pela Comissão Pastoral da Terra (CPT) sobre os conflitos no campo do Brasil têm demonstrado, desde 1985, um espaço agrário regado por um rio de sangue formado por centenas de pessoas que reivindicam o cumprimento da função social da terra e uma reforma agrária ampla e democrática. Contudo, perpetua-se a hereditariedade do latifúndio iniciado no processo de colonização e invasão europeias, o qual, mantendo-se até os dias atuais, reproduz um espaço agrário contemporâneo, formatado por uma colonialidade do poder, do saber e do ser (QUIJANO, 2005), gerenciando, assim, a vida de quem pode ou não ter terra, de quem vive ou morre.

\begin{tabular}{|c|c|c|c|c|c|c|c|}
\hline \multicolumn{7}{|c|}{ Quadro 01 - Comparação dos Conflitos no Campo Brasil (1985 - 2019) } \\
\hline Ano & $\begin{array}{c}\mathrm{N}^{\circ} \text { de } \\
\text { conflitos }\end{array}$ & $\begin{array}{c}\text { Pessoas } \\
\text { Envolvidas }\end{array}$ & Assassinatos & Ano & $\begin{array}{c}\mathrm{N}^{\circ} \text { de } \\
\text { conflitos }\end{array}$ & $\begin{array}{c}\text { Pessoas } \\
\text { Envolvidas }\end{array}$ & Assassinatos \\
\hline 1985 & 768 & 567.354 & 216 & 2003 & 1.690 & 1.190 .578 & 73 \\
\hline 1986 & 759 & 810.856 & 177 & 2004 & 1.801 & 975.987 & 39 \\
\hline 1987 & 782 & 1.363 .729 & 218 & 2005 & 1.881 & 1.021 .355 & 38 \\
\hline 1988 & 680 & 684.513 & 110 & 2006 & 1.657 & 783.801 & 39 \\
\hline 1989 & 566 & 536.513 & 68 & 2007 & 1.538 & 795.341 & 28 \\
\hline 1990 & 448 & 557.619 & 79 & 2008 & 1.170 & 502.390 & 28 \\
\hline 1991 & 426 & 549.319 & 54 & 2009 & 1.184 & 628.009 & 25 \\
\hline 1992 & 433 & 185.996 & 46 & 2010 & 1.186 & 559.401 & 34 \\
\hline 1993 & 545 & 391.120 & 52 & 2011 & 1.363 & 600.925 & 29 \\
\hline 1994 & 485 & 308.619 & 47 & 2012 & 1.364 & 648.515 & 36 \\
\hline 1995 & 554 & 381.086 & 41 & 2013 & 1.266 & 573.118 & 34 \\
\hline 1996 & 750 & 935.134 & 54 & 2014 & 1.286 & 817.102 & 36 \\
\hline 1997 & 736 & 506.053 & 30 & 2015 & 1.217 & 816.837 & 54 \\
\hline 1998 & 1.100 & 1.139 .086 & 47 & 2016 & 1.536 & 909.843 & 61 \\
\hline 1999 & 983 & 706.361 & 27 & 2017 & 1.431 & 708.520 & 71 \\
\hline 2000 & 660 & 556.030 & 21 & 2018 & 1.489 & 960.342 & 28 \\
\hline 2001 & 880 & 532.772 & 29 & 2019 & 1.833 & 859.023 & 32 \\
\hline 2002 & 925 & 451.277 & 43 & & & & \\
\hline
\end{tabular}

Fonte: CPT-Nacional. Org.: o autor. 
Os números do quadro 01 apontam para uma questão agrária no Brasil pautada pelo conflito e pela violência, criando um "martirológio" de pessoas assassinadas e desaparecidas, cuja trajetória de vida reflete em cicatrizes profundas oriundas da luta pela terra. Apesar dos números de conflitos e mortes no campo brasileiro estarem constantes desde antes de 1985 até os dias atuais, chamamos a atenção para três contextos políticos que são acompanhados por uma elevação do número de assassinatos. O primeiro refere-se ao período de abertura política/democrática do país (entre 1985 e 1988). O segundo contexto, em 2003, caracteriza-se pelo momento marcado pelo início do governo de Luiz Inácio Lula da Silva. O último contexto dá-se com o golpe parlamentar contra a ex-presidenta Dilma Rousseff, momento em que novamente houve aumento do número de mortes em conflitos agrários no Brasil.

Não será pauta deste artigo a discussão desses contextos políticos mencionados, mas eles nos servirão de exemplos para entender que os conflitos agrários no Brasil não podem ser desvinculados da política, para a qual as ações de violência representam instrumento político para reprimir as forças contra-hegemônicas, impedindo, assim, as reivindicações dos direitos sociais no campo e na cidade.

De modo geral, os dados levantados pela CPT sintetizam a complexidade da questão agrária brasileira, principalmente por revelar números expressivos de conflitos, e de pessoas envolvidas e assassinadas. Isso evidencia a conformação de um espaço agrário constituído por uma assimetria de poder, na qual existe instrumentalização política favorável à manutenção da propriedade privada da terra na representação territorial do latifúndio, mesmo que improdutivo, grilado ou os dois simultaneamente.

Os conflitos no campo emergem quando forças contra-hegemônicas contestam as irregularidades dessas propriedades privadas da terra, para as quais a violência é um instrumento político de contenção desses movimentos insurgentes e reivindicatórios. Assim tem sido a realidade agrária do Brasil desde o processo de colonização.

\begin{abstract}
A violência como forma de tratamento dos trabalhadores do campo é parte integrante do chamado padrão tradicional de dominação na história brasileira. Os massacres indígenas para permitir a apropriação das terras por eles ocupadas, a escravidão negra, a subordinação dos homens "livre e pobres", as formas de controle frequentemente denunciadas pelos colonos europeus que vinham trabalhar nas lavouras de café e que encontravam nas queixas a seus consulados uma saída alternativa para provocar uma reordenação nas relações de trabalho, foram algumas das expressões da violência no meio rural. Ela fez-se sentir ainda mais fortemente em situações de resistência coletiva, como as de Canudos e do Contestado, nas quais o Exército foi inclusive chamado a intervir (MEDEIROS, 1996, p. 5).
\end{abstract}

Para Medeiros (1996), a violência tornou-se uma prática usual para recobrir situações fundiárias irregulares e o sistemático descomprimento da legislação trabalhista, não sendo, portanto, um fenômeno novo, mas uma forma de tratamento que tem transcedido no tempo, produzindo um espaço agrário setenciado por uma política da morte física, social/moral e espiritual. Isso corresponde a um problema social e a uma questão agrária no Brasil apontados pela vulnerabilidade de grande parcela da população do campo - e da floresta - que estão expostas a ações de diferentes formas de violência e à expropriação da terra e da vida. Desse modo, entende-se a violência como "leque de práticas que indicam um não reconhecimento dos trabalhadores do campo como portadores de direitos e, portanto, sujeitos a diferentes formas de submissão que têm a coerção como o parâmetro mais visível" (MEDEIROS, 1996, p. 3).

Partindo dessa problemática, o objetivo deste artigo é compreender a natureza dos conflitos agrários e das formas de violência que ocorrem na fronteira amazônica a partir de 1950, levando em 
consideração a inserção dessa região no cenário político e econômico do capitalismo brasileiro e mundial. Busca-se com isso fazer uma geo-história das cicatrizes da luta pela terra na Amazônia.

Os conflitos agrários intensificaram-se nessa região a partir da segunda metade do século XX, para os quais a disputa da natureza (terra, água, floresta, subsolo) é o elemento balizador para os focos de tensão social que vão eclodir incessantemente. A abertura da fronteira não promoveu uma partilha simétrica da natureza que, transformada em recurso econômico, tornou-se alvo dos capitais nacional e estrangeiro. A cobiça pelo solo amazônico desterritorializou a população local e foi sedimentada pelos órgãos estatais enquanto processo de colonização sobreposto às terras tradicionalmente ocupadas.

A política de incentivos para a Amazônia constituiu-se enquanto necropolítica (MMEMBE, 2019), na qual camponeses e indígenas foram condenados à inclusão no excludente progresso e reprimidos pelas forças hegemônicas a se manterem estáticos diante da quimera do desenvolvimento. Para Hébette (2004, p. 33), "inevitavelmente, surgiram os conflitos, pois a necessidade empurra o povo como o lucro impulsiona o capital. Toda a Amazônia tornou-se um imenso campo de tensões entre classes em torno dos seus recursos: terra, madeira, minério, uso da água."

E diante desse cenário forma-se um espaço agrário em constante tensão, ocasionado por uma racionalidade distinta de uso da natureza, levando à conformação de uma fronteira do humano na Amazônia, a qual pode ser dimensionada por meio da terra de trabalho e terra de negócio (MARTINS, 2009; 1980).

Desse modo, compreende-se a fronteira como "ponto limite de territórios que se redefinem continuamente, disputados de diferentes modos por diferentes grupos humanos." "Nesse sentido, a fronteira tem um caráter litúrgico e sacrifical, porque nela o outro é degradado para, desse modo, viabilizar a existência de quem o domina, subjuga e explora" (MARTINS, 2009, p. 10-11).

Ao passo que homens e capital avançam na fronteira amazônica, os focos de tensão foram gradualmente aumentando na velocidade das queimadas que abrem clareiras no interior da floresta. Esse fogo que limpa o solo após a retirada da madeira para a implantação da pecuária é o mesmo fogo que queima casas e roças e faz crescer o número de mortes no campo.

A partir dessa perspectiva, entende-se que os conflitos agrários que se dilatam no interior da fronteira amazônica não se mantêm apenas em razão da disputa da natureza, mas são acompanhados por uma intensa ação de violência contra a população que resiste à expropriação da terra.

A resistência camponesa-posseira sofre fortes retaliações do Estado e dos agentes capitalistas que tentam neutralizar a luta pela terra. A assimetria de força e de poder, coloca esse movimento na mira da violência física, moral e psicológica que tem levado a grande número de óbitos de camponeses, religiosos, sindicalistas, lideranças, advogados, entre outros que tentam frear as cercas dos latifúndios. Esse estado de tensão, conflito e violência torna-se constante na vida camponesa na Amazônia, complexificando, assim, a produção do espaço agrário regional.

A partir dos dados históricos e geográficos dos conflitos agrários na fronteira amazônica, defende-se aqui a tese de que a territorialização camponesa nessa região acompanha os intensos conflitos e ações de violência no campo. A resistência camponesa em continuar a fazer do campo a morada da vida (HEREDIA, 1979) gera os conflitos com os latifundiários especuladores e grileiros que agem com violência para reprimir as forças contra-hegemônicas. Desse modo, o campesinato da fronteira emerge por dentro da luta pela terra que desemboca em conflito e violência, dentro da qual este campesinato consegue, por meio do confronto contra as ações do capital e do Estado, territorializar-se nas ocupações da terra até a conquista do território, o assentamento rural. 
Com base nos números dos conflitos agrários de 2003, Porto-Gonçalves (2004) desvenda a existência de três dimensões das lutas sociais no campo brasileiro, as quais correspondem ao debate deste trabalho, sendo elas: 1) grau de conflitividade e envolvimento da sociedade, com a evolução do quadro agrário, destacando o número de pessoas envolvidas em conflitos; 2) o papel do poder público - a ação do poder judiciário e repressivo (aparelho policial); 3) o papel e a ação do poder privado no campo - os latifundiários.

Essas três dimensões das lutas sociais no campo apareceram simultaneamente na pesquisa documental dos conflitos agrários no acervo arquivístico da Comissão Pastoral da Terra, com sede em Xinguara, sul do Pará. As reflexões e considerações que se pretendem realizar neste artigo vêm de resultados de projetos de extensão e de pesquisa realizados a partir do acervo dessa entidade política.

O projeto teve como objetivo contribuir com a recuperação, o tratamento e a digitalização do acervo arquivístico disponível na CPT. Por meio dessa relação com a Comissão Pastoral da Terra, tem-se a oportunidade de analisar e disponibilizar dados e acontecimentos importantes acerca da memória dos conflitos agrários da região pesquisada, contribuindo para a compreensão da formação da fronteira amazônica, por meio da pesquisa nos arquivos de conflitos e mortes no campo. A partir desse acervo, descobrimos diversos conflitos pela terra que se apresentam como cicatrizes profundas no espaço agrário regional, de forma particular no sul e sudeste do Pará.

Conflitos pela concentração fundiária, conflitos pela demarcação de terras indígenas, conflitos pela preservação ambiental, conflitos pela extração devastadora de recursos naturais, conflitos pela construção de megainfraestruturas, conflitos pela expansão do agrohidronegócio, conflitos pelo controle da produção de alimentos, conflitos pela manutenção de formas de vida tradicionais, conflitos pela expropriação, expulsão e exclusão dos camponeses e dos povos e comunidades tradicionais, conflitos pela implementação de estratégias de desenvolvimento (MONTENEGRO, 2010, p. 13).

Esta lista atravessa o acervo, compondo, portanto, um patrimônio material da memória dos conflitos agrários e das lutas pela terra no contexto de maior inserção da Amazônia no capitalismo global. A recuperação dessa memória foi a ação de mediação para a nossa compreensão do espaço e dos movimentos insurgentes tanto no campo como também na cidade.

Para este artigo, selecionamos quatro casos que representam uma síntese dos conflitos encontrados no acervo: conflito de Itaipavas, em Conceição do Araguaia; conflitos na região do Araguaia/Tocantins; Fazenda extrema no Tocantins; e casos de assassinatos no sul do Pará. A partir desses exemplos, busca-se apresentar uma amostra da natureza dos conflitos agrários na fronteira amazônica que demarcam a geo-história das cicatrizes da luta pela terra na região. 


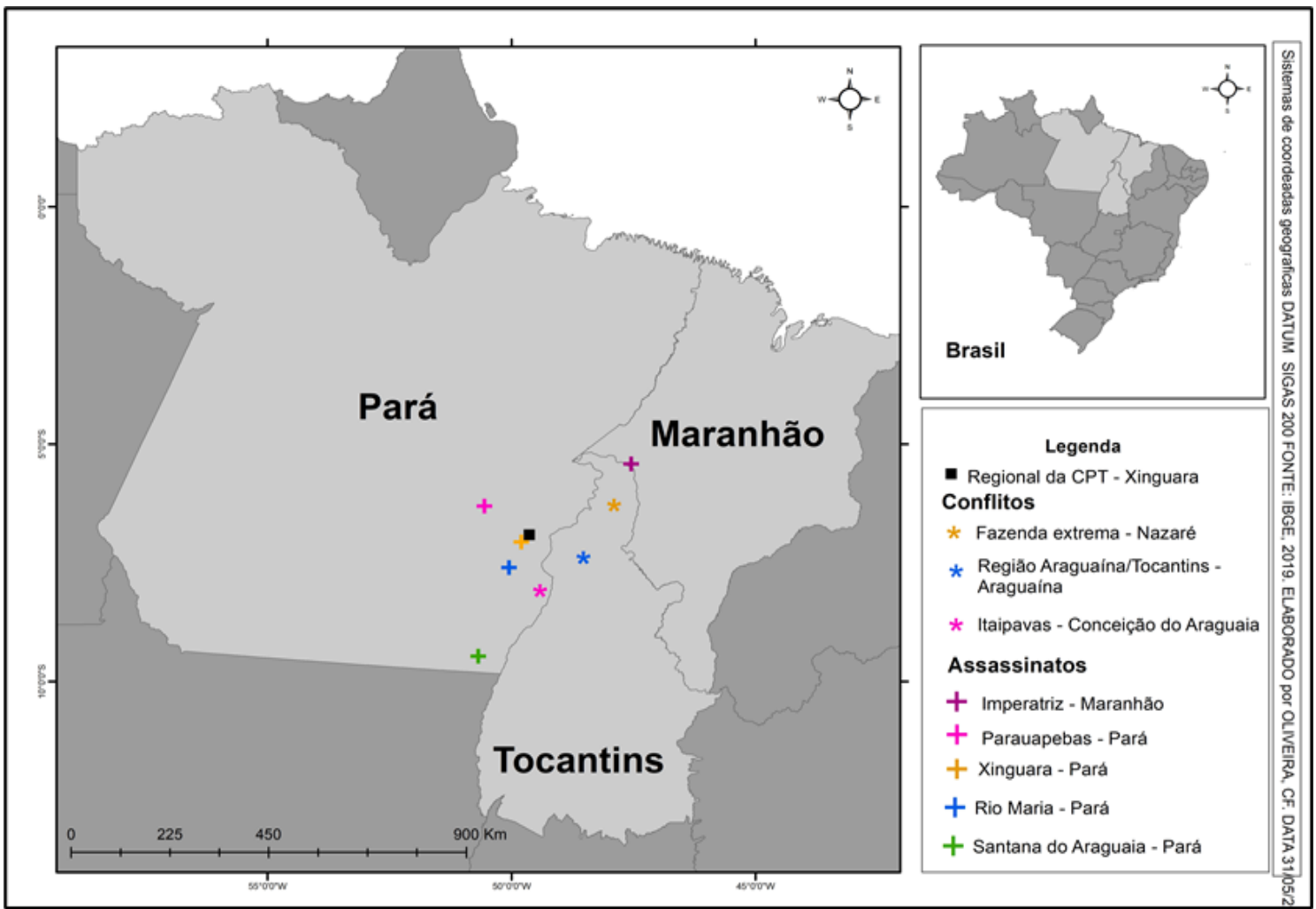

No mapa 01, observa-se a localização da Regional da CPT na qual foi desenvolvida a pesquisa documental e os conflitos, e assassinatos que analisamos para a construção deste trabalho. Notase, que os casos em tela estão imbricados em uma das regiões mais conflituosa do Brasil, conhecida como Bico do Papagaio, na fronteira administrativa entre os Estados do Maranhão, Pará e Tocantins.

Como metodologia, realizou-se, portanto, a análise documental desses casos mencionados e de outros que nos dão embasamento para a produção do debate proposto à luz de referências bibliográficas que elucidem as questões levantadas no trabalho. Os conflitos que foram analisados durante a pesquisa datam entre as décadas de 1960 até a de 1990.

$\mathrm{O}$ artigo segue dividido em duas sessões. Na primeira parte, busca-se discutir a natureza dos conflitos agrários e de como ocorrem as formas de violência, expropriação e luta pela terra na fronteira amazônica. Na segunda, atenta-se às situações de mortes no campo como um instrumento político para conter os movimentos insurgentes, a banalidade dos assassinatos e das impunidades dos assassinos e mandantes.

\section{A geografia dos conflitos agrários e a violência na fronteira amazônica}

A abertura da fronteira amazônica, a partir de 1950, criou um espaço de tensão entre forças antagônicas que, ao longo das décadas transformou essa região em uma das de maior conflito agrário do Brasil. A privatização da terra/floresta/subsolo por agentes econômicos nacionais e estrangeiros, levou o sul e sudeste do Pará ao epicentro da exclusão de posseiros, extrativistas e indígenas que, desterritorializados, entraram na luta pela terra e território.

Expande-se a partir de então grandes projetos camuflados pelo slogan do desenvolvimento, entre eles: Projeto Grande Carajás, Hidrelétrica de Tucuruí, incentivos à pecuária, madeireiros, garimpos e infraestruturas - rodovias, ferrovias, portos. Esses empreendimentos ressignificaram as 
velhas oligarquias do caucho e da castanha, que nos dias atuais podem ser entendidos como agronegociantes.

O processo de colonização que se instaurou pelas mãos do Estado foi sobreposto às terras tradicionalmente ocupadas, não levando em consideração a população que historicamente já habitava a região. Juntam-se às famílias expulsas da terra, centenas de migrantes camponeses que chegam à região em busca de terra, trabalho e melhoria de vida. Muitos expulsos da cerca e da seca nordestina, chegam à Amazônia com o sonho da terra prometida, anunciada pelo tema de "terra sem homens, para homens sem-terra".

Na América Latina, a última grande fronteira é a Amazônia, em particular a Amazônia brasileira, [...]. Desde o início da conquista, foi ela objeto de diferentes movimentos de penetração: na caça e escravização do índio, na busca e coleta das plantas conhecidas como "drogas do sertão", na coleta do látex e da castanha. A partir do Golpe de Estado de 1964 e do estabelecimento da ditadura militar, a Amazônia brasileira transformou-se num imenso cenário de ocupação territorial massiva, violenta e rápida, processo que continuou, ainda que atenuado, com a reinstauração do regime político civil e democrático em 1985 (MARTINS, 2009, p. 132)

Martins (2009, p. 132) salienta que "a história do recente deslocamento da fronteira é uma história de destruição. Mas é também uma história de resistência, de revolta, de protesto, de sonho e de esperança". Observa-se, assim, na perspectiva do autor, que a formação territorial da fronteira é "essencialmente o lugar da alteridade", onde coexistem forças assimétricas de poder, do saber e do ser, resultantes de temporalidades adversas, conformando uma base territorial estigmatizada pelo conflito entre classes sociais antagônicas.

Para Martins (2009, p. 133), a fronteira, e de forma particular a amazônica, configura-se como o lugar de encontro entre grupos humanos diferentes e, ao mesmo tempo, do desencontro entre concepções de vida e visões de mundo distinto, abrindo-se, assim, ao desencontro de temporalidades opostas. Desse modo, o autor conclui que "o conflito faz com que a fronteira seja essencialmente, a um só tempo, um lugar de descoberta do outro e de desencontro."

Nesse campo em disputa, constituiu-se um processo de expropriação e violência, o qual tem levado a população camponesa e indígena a episódios de expulsão da terra, em muitos casos, com mortes.

Entende-se, a partir de Martins (2009), que o que caracteriza e define a fronteira no Brasil é justamente a situação do conflito social, marcado, primordialmente, pela luta por terra. Daí, explicitase a tese aqui defendida de que a territorialização camponesa na fronteira amazônica, a partir de 1950, formou-se mediada por conflito e violência, na qual, por meio da resistência e do enfrentamento, os camponeses têm conseguido permanecer no campo, realizando um processo de campesinização por entre as fissuras da terra de negócio.

Assim, o campesinato da fronteira, além de ter a migração como característica, tem no conflito e na violência as especificidades que marcam a trajetória de vida, seja quando são expropriados de suas posses, seja quando se territorializam nas ocupações em luta pela terra. Mesmo que a atual geração de camponeses assentados não tenha vivenciado situações de conflito e de violência, muito provavelmente gerações antecedentes conheceram de perto esses estigmas da vida na fronteira.

A articulação dos camponeses com a Comissão Pastoral da Terra e com os Sindicatos dos Trabalhadores Rurais tornou-se um caminho de mediação na luta pela terra, para a qual estas entidades configuram-se como suporte para os camponeses terem acesso ao conhecimento jurídico e político de seus direitos sociais. Neste contexto, os camponeses encontram forças junto às entidades que os apoiaram na luta, direcionando-se inicialmente à "Igreja - principalmente, no caso, 
a Igreja Católica -, aos partidos de esquerda, na época clandestinos, e à Sociedade Paraense de Defesa dos Direitos Humanos (SPDDH)" (HÉBETTE, 2004, p. 196).

No caso particular da Igreja Católica, nos anos de 1960 e 1970, esta estava passando por uma transformação interna, principalmente referente à ala mais progressista no interior da própria Igreja. Após as Assembleias Episcopais de Medellín e Puebla e o surgimento das contestações sociais da teologia da libertação, tem-se no Brasil, em 1975, a criação da Comissão Pastoral da Terra, com sede nacional em Goiânia. As seções locais de Conceição do Araguaia (sul do Pará), - hoje sediada em Xinguara - e Marabá (sudeste do Pará), bastante engajadas, passaram a atuar junto aos camponeses na luta pela terra (HÉBETTE, 2004).

Assim, desde 1975 a CPT tem atuado e acompanhado a luta pela terra na fronteira amazônica, organizando política e socialmente os camponeses e orientando-os nos casos judiciais de desapropriação da terra, de despejos e assassinatos. No quadro a seguir ilustra-se um dos conflitos encontrados no acervo da entidade em Xinguara, tal situação também vivenciada pelos posseiros em Conceição do Araguaia, reproduz-se no interior da fronteira amazônica como mecanismo de expropriação camponesa da terra.

Quadro 02 - Conflito Itaipavas

O Caso Itaipavas

Itaipavas se localiza à margem esquerda do rio Araguaia, a $300 \mathrm{~km}$ de Conceição do Araguaia, sede do município. Ali viviam pacificamente, sem grandes ambições e graves problemas, algumas centenas de famílias, quando começou o movimento dos grandes latifúndios.

Itaipavas ficou praticamente cercada: na frente o rio Araguaia, nos lados e no fundo, os grandes proprietários de terra. Diminuíram para os moradores as possibilidades de expansão e até de sobrevivência, já que restavam poucas glebas de terras devolutas e mesmos estás estavam sendo cobiçadas pelos homens de dinheiro. Essas dificuldades foram amplamente explicadas, explanadas ao governo municipal e estadual, e pedidas as providencias.

No dia 21 de maio de 1970, no Diário Oficial em seu número 21.788, saiu edital do Governo do Estado do Pará fazendo uma reserva das Glebas 7, 17, 18, 20, 21 e 22 para os posseiros de Itaipavas, presentes e futuros. Com isso o povo se animou e começou a plantar suas roças nos ditos lotes, sobretudo no lote 7 (nos fundos de Itaipavas) e no 22 logo acima. O lote 22 (antigo Banana Come) foi aos poucos ocupado pelos proprietários da Fazenda São José, que indenizaram os posseiros.

O lote 7 começou a ter uma história especial. Um cidadão paulista por nome de Geraldo Beraldo comprou alguns lotes na região de Itaipavas, de Luso Solino, e mandou fazer a demarcação. Não se contentou, porém, com as terras compradas, mas estendeu o seu "império" as outras áreas incluindo também parte das áreas reservadas pelo edital do Governo. 0 lote 7 foi a área mais cobiçada, já que ali viviam umas 40 famílias com suas roças plantadas e outros benefícios. Em 1975, Geraldo Beraldo pediu aos posseiros que assinassem uma carta de agregados, alguns não entendendo bem, assinaram, outros se recusaram assinar. Depois de um ano, ele apareceu para retirar os posseiros. Estes não saíram. Sairiam sim se quem se dizia dono da terra apresentassem o título da terra, o que nunca fez. Geraldo Beraldo partiu então para as ameaças. Mandou prender muita gente, comprando a polícia. Os seus capatazes Deusdete e Ireno fizeram muita maldade com os posseiros. Geraldo entrou [n]a justiça de Conceição. Em março de 1976, a Juíza, Dra. Emilia, completamente ausente dos problemas da Comarca, vivendo mais em Belém, e também, conforme a voz popular, "engraxada" pelo Geraldo Beraldo, sem ouvir os posseiros, sem mandar fazer uma vistoria ao local, assinou uma liminar em favor de Geraldo Beraldo, e enviou o escrivão de Justiça e os soldados (no avião do Sr. Geraldo Beraldo) para despejar os posseiros.

Exatamente no dia 31 de março de 1976, os posseiros acatando a ordem da Juíza, a pedido de D. Estevão e do advogado Dr. Sergio Guimarães, deixaram pacificamente suas posses, suas roças, com arroz maduro, seus mandiocais, o arroz colhido dentro de casa, as galinhas, os porcos... Saiam do Lote chorando, mas mesmo assim, desfraldaram a bandeira brasileira e cantaram o hino nacional. No dia primeiro de abril pela manhã a polícia foi fazer o mesmo despejo de posseiros em Luzilândia, a 8 km de Itaipavas. Ali a coisa não [foi] pacífica. Um dos posseiros atirou no capataz de Geraldo Beraldo, que por infelicidade pegou no sargento da polícia, que foi ferido, mas não morreu. Com isso, a coisa engrossou. Começaram as prisões a torto e direita. A polícia jogou a culpa de atentado pessoal de Itaipavas, completamente por fora do curso. Aí começou o desmando. Muitos foram torturados para contar o nome do mandante do crime. Vinte e oito homens de Itaipavas foram levados pela polícia, entre eles o Pedro Barreira - há 34 anos em Itaipavas - os seus filhos João e Francisco e seu genro Gringo. Os presos foram levados para Conceição onde ficaram 


\begin{abstract}
vinte dias. Depois de interrogados alguns foram soltos, outros foram levados para Marabá. O João Barreira ficou 47 dias preso. O Gordinho, o Tião, o Paraíba ficaram vinte dias em Marabá. No interrogatório dos presos perguntaram muito pelas atividades de D. Estevão, de Frei Henrique e do Dr. Sergio. No depoimento escrito que leram para o João Barreira assinar havia uma acusação formal aos mesmos como insufladores da "revolta" de Itaipavas. O João Barreiro recusou-se a assinar afirmando que nunca disse aquilo. Eles, ao contrário, evitaram um conflito de grandes proporções em Itaipavas. A polícia teve que reformar o depoimento. A polícia de Marabá, um belo dia, recebeu ordem de soltar os presos sem nunca dizer por qual "crime" eles foram presos.

O Sr. Geraldo Beraldo sem os posseiros no lote 7, deixou passar algumas semanas. Vendeu-o em seguida a um tal Neife. Este enviou pra lá homens armados (inclusive paraguaios) que começaram o serviço de desmanchar o que lá existia para plantar capim.

Hoje, 3 de março de 1977, faz exatamente um ano que os posseiros saíram. Tiveram um prejuízo total sem nenhuma indenização. Perderam tudo: suas casas, suas roças já com arroz e milho maduros ou já apanhados, suas mandiocas, suas galinhas, seus porcos. Foram trabalhar nas fazendas para poder sustentar suas famílias. Foram proibidos de buscar um grão de arroz nos seus ranchos e suas roças. Com isso, tiveram que comprar seus mantimentos. Suas armas de caça (40 ao todo) foram simplesmente carregadas e não restituídas até hoje. As mulheres e crianças passaram fome. O que valeu foi a solidariedade humana e caridade cristã do povo de Itaipavas. Salvos raras exceções de alguns que recebiam dinheiro de Geraldo Beraldo. O Dr. Sergio Guimarães entrou com um processo tentando derrubar a liminar da Juíza. Um ano se passou e até agora a justiça nada decidiu. Parece completamente ausente. Como Pilatos está lavado as mãos. Que os pobres sofram, que os posseiros se danem. Um crime que brada aos céus.

Conceição do Araguaia, 31 de março de 1977
\end{abstract}

Fonte: Acervo CPT/Xinguara. Org.: o autor

O conflito em Itaipavas, no município de Conceição do Araguaia, sul do Pará, retrata um dos inúmeros e diversos conflitos agrários na fronteira amazônica, nos quais a grilagem e a expropriação posseira são alguns elementos centrais do processo de formação dos latifúndios nessa região.

Por este conflito em particular, observa-se inicialmente o cercamento das terras dos posseiros por fazendeiros, caracterizando-se, portanto, como uma das primeiras formas de pressão sobre a propriedade camponesa. Quanto mais o latifúndio avança no espaço agrário, mais difícil torna-se a reprodução social familiar camponesa, ocasionando, simultaneamente, em fluxos migratórios para lugares distantes da terra de seus progenitores. Tem sido assim parte do percurso do campesinato brasileiro.

A trajetória de vida dos camponeses na fronteira amazônica é acompanhada por expulsões da terra, sejam daqueles que migraram de outras regiões, principalmente do Nordeste, sejam daqueles que tradicionalmente já ocupavam a Amazônia. Desse modo, entende-se que uma mesma geração familiar posseira pode vivenciar várias ações de violência e expropriação da terra.

No quadro 02, percebe-se a atuação de fazendeiros do Sudeste brasileiro no processo de grilagem de terra na Amazônia, agindo de forma arbitraria para a expropriação dos posseiros com a anuência do poder judiciário local. Ao vender a propriedade das famílias camponesas meses depois do despejo, evidencia-se a aquisição de terra para especulação, situação recorrente no processo de concentração fundiária no Brasil.

Por outro lado, observa-se o processo de grilagem de terra em Itaipavas. Essa forma de usurpação da terra tornou-se mecanismo para os fazendeiros aumentarem suas propriedades, as quais, mesmo sendo ilegais, propiciam-os enquanto beneficiários pelo poder judiciário local.

O processo de grilagem é clássico. Junta-se à documentação para a aquisição de terras "devolutas" dos estados, duas certidões sempre "negativas" da existência, naquela terra a ser titulada, de índios e/ou posseiros. Essa falsificação tem em vista contornar dispositivos das constituições brasileiras que garantem o direito dos índios sobre suas terras e dos posseiros sobre suas posses. Depois dos documentos, na grande maioria falsos, o órgão competente dos estados (Instituto de Terras) expede os títulos de propriedade da terra requisitada, sem que ninguém, nem mesmo os técnicos (agrimensores, engenheiros, etc) que assinaram as plantas de localização e de amarração tenham estado lá. São conhecidos como "títulos 
voadores", "títulos de prancheta. A partir daí acontece o absurdo jurídico: o posseiro e o índio são transformados em "invasores" da propriedade privada titulada" (OLIVEIRA, 1988, p. 64).

Em Oliveira (1988), explicita-se o processo de grilagem da terra que aconteceu em Itaipavas, no qual o fazendeiro disse ser o dono da terra já ocupada pelos posseiros. A transformação jurídica dos posseiros em invasores materializa-se nas ordens de despejo, por isso "a violência é um instrumento do processo de grilagem e dele não pode ser dissociado" (OLIVEIRA, 1988, p. 65).

Parte dos casos de conflitos disponíveis no acervo arquivístico da CPT-Xinguara, encontra-se a ação conjunta de policiais e de seguranças particulares dos fazendeiros que ativaram o processo de reintegração de posse da terra, como é o visto no caso de Itaipavas. Essa ação conjunta demonstra o elo de forças entre o poder judiciário e os latifundiários nos casos de despejos dos posseiros.

Observa-se nesse caso a ação do poder judiciário e do poder privado dos latifundiários já em 1977, sendo destacado por Porto-Gonçalves (2004) como duas das três dimensões das lutas sociais no campo a partir das análises dos conflitos em 2003 no Brasil. Isso demonstra que no rural, o qual se imagina moderno e tecnológico, coexistem velhas práticas de coerção e violência, sentenciando de fato quem tem direito ou não à terra.

As formas de despejos das famílias são marcadas pelas violências física, moral e psicológica. Quando não há confronto direto, de força armada, há a perda dos bens indispensáveis para a reprodução social da família. Roças, produções agrícolas, animais, casas, bens materiais são deixados para trás no intuito de garantir a própria vida. A destruição, ou mesmo a proibição de acesso dos camponeses aos bens materiais, principalmente alimentos, é uma violência moral para aqueles que vivem do que plantam e colhem. Perdendo não apenas os produtos, mas também o trabalho que foi empregado na construção e na manutenção da roça e na criação de animais.

Esses casos de conflitos decorrentes de ações judiciais com despejo de posseiros são evidenciados nos estudos de Loureiro. Para a autora,

\begin{abstract}
Uma das causas frequentes de conflitos por terra e de seu agravamento tem sido o resultado das ações judiciais nas quais o juiz manda retirar os posseiros, reintegrar o proprietário na terra, devolvendo-a a ele através de força policial. A polícia atua no cumprimento dessas ações, expulsando os posseiros e suas famílias, em geral, com violência. Dependendo na história social anterior dos posseiros (número de migrantes e expulsões anteriores, mortes entre membros do grupo ou em grupos vizinhos e do nível de tensão no momento do cumprimento da ação judicial), os acontecimentos se tornam imprevisíveis, se houver resistência dos posseiros à ordem de saírem da terra (LOUREIRO, 2004, p. 250).
\end{abstract}

As considerações de Loureiro (2004) retratam tanto o conflito ocorrido em Itaipavas, onde os posseiros saíram da terra pacificamente, como também em Luzilândia, onde houve o confronto entre os posseiros e os policiais e seguranças particulares (pistoleiros e milicianos) do fazendeiro. Por esses exemplos, nota-se que as ações de despejos ganham reforços humanos por parte do fazendeiro, que oferece apoio com seus seguranças aos policiais no ato da expulsão, dando por vezes ordens que extrapolam a sentença do caso, violando, assim, os direitos humanos no cumprimento da ordem judicial (LOUREIRO, 2004).

Entende-se desse modo, que o conflito nasce quando a terra passa a ser disputada entre os posseiros e os que se dizem donos da propriedade. A violência aparece nesse processo materializado nas ordens de despejos, que podem ocorrer por meio da violência física, como em Luzilândia, ou somente de violência moral e psicológica, como aconteceu em Itaipavas. Em ambos casos, observase que a violência é sentida predominantemente pelos posseiros, como é evidenciado nos conflitos presentes nos arquivos da CPT. 
As condições de amadurecimento do conflito por terra na fronteira amazônica acontecem em um primeiro momento a partir do aliciamento por parte dos fazendeiros e seus capatazes (pistoleiros e milicianos) para que os posseiros deixem a propriedade. Cerceados e coagidos pelo poder de fogo dos ruralistas, os posseiros buscam alianças junto aos sindicatos, à CPT, a religiosos e advogados que fazem a intermediação jurídica para que as famílias permaneçam na terra. Por outro lado, percebe-se que os fazendeiros são privilegiados pelas instâncias jurídicas e favorecidos pelas leis vigentes no Brasil (LOUREIRO, 2004).

O conflito e a violência em Itaipavas não terminaram com o fim do despejo, o desdobramento do caso continuou com prisões e perseguições, não somete das famílias que moravam na localidade, mas também de pessoas que instruíram política e socialmente os posseiros sobre os seus direitos. Nesse exemplo, observa-se a tentativa de criminalização de religiosos e advogados que fazem parte da luta pela terra e da organização dos camponeses nas reivindicações de seus direitos sociais.

Essas relações entre religiosos e camponeses, em algumas situações, foram alvo de difamações junto à sociedade local, inclusive com ações judiciais e, por vezes, ameaças de morte e/ou mesmo assassinatos.

\section{Quadro 03 - Conflito na região do Araguaia/Tocantins}

COMISSÃO PASTORAL DA TERRA - ARAGUAIA/TOCANTINS
Desde 3 meses uma onda de violência e de crimes está se desencadeando contra trabalhadores rurais no
Brasil e contra aqueles que apoiam suas lutas justas pelo direito à terra, lideranças religiosas, sindicais,
advogados, para impedir que uma lei sobre a Reforma Agrária em favor dos trabalhadores rurais seja incluída
na Constituição Federal.
O Padre Ricardo Resende Figueira, Coordenador da Comissão Pastoral da Terra Araguaia-Tocantins no norte
do Brasil, uma das regiões mais conflituosas do País, foi alvo, nestes dias, de ataques difamatórios muito
graves do presidente nacional da UDR, União Democrática Ruralista, através de um grande jornal de São
Paulo.
Ataques semelhantes foram feitos contra o Pe. Josimo Moraes Tavares antes de ser assassinado no dia
10.05.86, para justificar o crime.
Gurupí, 20 de setembro de 1987

Fonte: Acervo CPT/Xinguara. Org.: o autor

No quadro 03, observa-se a perseguição política contra religiosos que orientavam juridicamente os posseiros na luta pela terra. A criminalização dos movimentos sociais, de entidades políticas e das pessoas engajadas (religiosos, sindicalistas, advogados) que mediam os processos de regularização fundiária é uma tentativa de silenciar e frear as ações de desapropriação das terras improdutivas concentradas nas mãos de fazendeiros e grileiros.

O silenciamento acontece de fato com a morte dessas lideranças, como foi o caso do Padre Josimo Moraes Tavares ${ }^{3}$. Na década de 1980, o religioso denunciou fazendeiros que, "acobertados pelo poder público, fecham o cerco contra ele e as comunidades da região" do Bico do Papagaio (OLIVEIRA, 1988, p. 47).

Para Oliveira (1988), durante a transição das décadas de 1970 e 1980, a Amazônia concentrou a maior parte dos assassinatos no campo, principalmente no entrecruzamento dos Estados do Pará, Maranhão e Tocantins, mais o Mato Grosso. "Neste período, estas regiões assistiram aos assassinatos de posseiros, peões e, sobretudo de padres, advogados e novas lideranças sindicais."

3 "Religioso, coordenador da CPT da Região do Bico do Papagaio e membro do Conselho da CPT/Araguaia-Tocantins, morador do município de São Sebastião do Tocantins, foi assassinado a 10 de maio de 1986 na sede da CPT em Imperatriz, Maranhão" (OLIVEIRA, 1988, p. 47). 
O autor ressalta "que há uma coincidência entre esta área explosiva, e área de maior concentração de projetos agropecuários incentivados pela SUDAM" (OLIVEIRA, 1988, p. 38).

Entende-se, assim, que a expansão da agropecuária na fronteira amazônica foi acompanhada pelos intensos conflitos agrários que afloraram da disputa pela terra. Os assassinatos no campo, ao invés de reprimir e silenciar as vozes que lutam pela terra, intensificaram-se as denúncias contra as irregularidades de proprietários grileiros e dos ataques aos direitos humanos. A resistência e a persistência dos camponeses possibilitaram, por meio da luta, a conquista do direito à terra, como o visto no caso a seguir.

\section{Quadro 04 - Conflitos da Fazenda Extrema - Nazaré/TO}

\section{BREVE HISTÓRICO DOS ACONTECIMENTOS NA FAZENDA EXTREMA, MUNICÍPIO DE NAZARÉ -} TOCANTINS

Ano 1917 - Desde esta época havia cerca de 200 famílias de posseiros residindo nos povoados Tamboril, Taboca e Centro dos Borges, e trabalhando na fazenda Extrema.

1973/1980 - Iniciou-se o processo de grilagem das terras dos posseiros, intensificando-se o conflito a partir da aquisição de 10.600 ha pela fazendeira Odicia da Conceição de Fátima Morais, residente em Goiânia-GO. Neste período dois despejos violentos ocorreram, inclusive com a queima de um povoado onde residiam 115 famílias.

1981/1983 - Neste intervalo três novos despejos ocorreram a partir de liminares concedidas pelos juízes de Tocantinópolis, Domingos Gomes de Almeida, e de Araguaína, João Batista de Castro Neto. (08.10.82 07.01.83; 05.02.83).

A execução desses despejos aconteceu de forma arbitrária, efetuados pela polícia acompanhada de pistoleiros da fazenda e sem a presença de oficial de justiça. Casas foram queimadas, roças destruídas, trabalhadores espancados e morte.

No início de fevereiro de 1983 foi morto o "gerente" da fazenda Cariolando Cardoso Silva, sendo desconhecida a autoria do crime.

Quando o despejo de 25.02.83, o lavrador Guardiano de Sousa Nascimento, 77 ano, teve sua casa invadida por 06 policiais por volta das 04 horas da madrugada, sendo muito torturado. Seu sobrinho Rufino Coelho Neto tentou socorrê-lo e foi morto a tiros pelos policiais. Posteriomente, foram à casa de outros posseiros e com violência, sequestraram dois posseiros, João Alexandre da Conceição e João Rufino Morais de Sousa, levando-os à residência do gerente da fazenda e apresentando-os como autores da morte do "gerente" (pistoleiro) Cariolano e obrigando-os a assinarem documentos que desconheciam o teor.

1984 - Em maio deste ano, os posseiros conseguiram na justiça, Liminar de manutenção de posse e em seguida foram desapropriados 7.100 ha.

1987 - O restante da área foi desapropriada, totalizando cerca de 10.00 ha.

Hoje a situação na área é tranquila, residindo cerca de 100 famílias. Da morte do "gerente" foi instaurada ação penal contra 08 lavradores, sendo que destes, 05 foram pronunciados mesmo não havendo nenhuma prova da autoria nos autos: Alonso José Veloso, João Celino Morais de Sousa, Argemiro Pereira da Silva, Aldenor Rodrigues Marinho e Domingos Barros da Rocha.

O Júri popular está marcado para o dia 04.06 .93 as 13 horas do Fórum de Tocantinópolis. Este processo foi acompanhado pelo advogado da FETAET e posteriormente nomeado defensor público.

É de se observar que da morte do posseiro Rufino Coelho Neto, 23 anos, sequer foi aberto inquérito policial. O exame de corpo de delito foi realizado pelos próprios policiais acusados de sua morte.

\section{CONSIDERAÇÕES GERAIS SOBRE ESTE CONFLITO}

Pe. Josimo Morais, Lourdes Goi, Fr. Henri des Roziers e Dom Aloísio acompanharam durante anos está área até a desapropriação. Inúmeras denúncias foram feitas pela CPT dada a intensidade do Conflito. Este processo representa uma investida contra a Igreja e contra o movimento dos trabalhadores rurais organizados na região do Bico do Papagaio. Daí a necessidade de uma boa articulação no sentido de obter a absolvição dos trabalhadores indiciados.

Paraíso do Tocantins, 19 de maio de 1993.

Fonte: Acervo CPT/Xinguara. Org.: o autor

O conflito na fazenda Extrema demonstra as semelhanças nos processos de grilagem da terra na fronteira amazônica, havendo sempre a expropriação das famílias que já habitavam a terra. A 
pressão dos fazendeiros é vista por diversas situações em que empregam violência contra os posseiros, como a destruição de casas e roças, ou mesmo o atear fogo em toda comunidade, como está impresso nos documentos referentes a este conflito.

Assim como em Itaipavas, os camponeses dos povoados de Tamboril, Taboca e Centro dos Borges foram despejados de forma violenta, mais uma vez pela ação conjunta de pistoleiros a mando de fazendeiros e policiais. Contudo, de acordos com os escritos no arquivo, não houve a presença de um oficial de justiça, demonstrando a irregularidade da ordem de despejo. Entretanto, diferente do que ocorreu em Itaipavas, os posseiros do caso apresentado no quadro 04 conseguiram a desapropriação da fazenda na Justiça, reavendo a posse da terra depois de mais de uma década de conflito. Observa-se que a conquista da terra pelos posseiros dificilmente é efetivada por meios pacíficos, havendo sempre muita luta, mortes, violência física, moral e psicológica, perda de espécies vegetais, dentre outras ausências que são irreparáveis para as famílias.

A partir do mergulho no acervo arquivístico da Comissão Pastoral da Terra constatou-se que muitas mortes de camponeses seguiram sem solução dos casos, não havendo a prisão dos assassinos, nem dos mandantes. No quadro 04, observa-se que enquanto houve a criminalização dos posseiros pela morte do gerente da fazenda Extrema, a morte do posseiro Rufino Coelho Neto, 23 anos, até 1993, não tinha gerado abertura de inquérito policial, demonstrando mais um dos inúmeros casos de impunidade das mortes no campo. No próximo tópico, será dado ênfase às mortes e aos assassinatos no campo da fronteira, o que caracteriza uma realidade constante no agrário brasileiro.

\title{
"Martirológio da luta pela terra": a geografia das mortes na fronteira amazônica
}

\begin{abstract}
Em 1962, João Pedro Teixeira foi executado na Paraíba. Sua história virou filme: Cabra Marcado para Morrer (1984), de Eduardo Coutinho, é até hoje considerado o melhor documentário brasileiro. Teixeira era líder das Ligas Camponesas. A expressão "cabra marcado para morrer" foi cunhado[a] pelo poeta Ferreira Gullar - e sintetiza, hoje, a situação de muitos brasileiros que desafiam quem tem poder, propriedades e prestígio. (CASTILHO, 2012, p. 206)
\end{abstract}

As lutas sociais no campo brasileiro têm colecionado, em diferentes contextos históricos e geográficos, mártires que doaram suas vidas em prol de causas coletivas. Esse feito tem produzido um martirológio de pessoas mortas e uma lista de "cabra marcado para morrer" que definem a trajetória dos movimentos contestatórios no campo, a partir do sentenciamento e morte de seus líderes.

Conflito e violência têm sido características do Brasil desde o Período Colonial, passando pelo Império e pela República. Nesses 520 anos de formação territorial, tem sido incessante os movimentos insurgentes que contestam a ordem imposta e do progresso seletivo para uma pequena parcela da sociedade. Repressão e violência são fórmulas encontradas pelo Estado e pelos detentores dos poderes político e econômico para conter os movimentos de resistência que entram em conflito, em razão de mudanças no quadro de concentração fundiária, de renda e dos privilégios, os quais orquestram, com crueldade, os massacres e as morte de lideranças que estão historiagrafados nos livros didáticos, os mais recentes são noticiados nos meios de comunicação.

Somente no período democrático, após 1985, pode-se elencar a morte de Chico Mendes (1988) e Dorothy Stang (2005), e os massacres de Curumbiara (1995), Eldorado dos Carajás (1996) e Pau D'arco (2017). Salienta-se que muitas das conquistas sociais foram efetivadas após a visibilidade 
gerada com esses acontecimentos que constituem as cicatrizes da luta por terra e território no campo brasileiro. $\mathrm{O}$ assassinato de Chico Mendes colocou na ordem do dia o debate político sobre a necessidade de criação das reservas extrativistas no Acre; o mesmo ocorreu no caso da Irmã Dorothy, com os Projetos de Assentamento e Desenvolvimento Sustentável (PDS), em Anapu, e a conquista do Projeto de Assentamento 17 de Abril pelos camponeses envolvidos no massacre de Eldorado dos Carajás. Contudo, nem todos os casos de assassinatos no campo tiveram grande repercussão, ou mesmo familiares e pessoas envolvidas em conflitos foram indenizados, entrando apenas nas estatísticas dos crimes e da impunidade no campo.

Castilho (2012, p. 205) destaca que somente "entre 2001 e 2010, foram assassinados no país 377 pessoas por conflitos no campo", envolvendo crimes na ordem da "pistolagem, conflitos ambientais, questão indígena e quilombola, expulsão de posseiros." Esse fenômeno da morte no campo é uma herança que tem se mantido no Brasil, estabelecendo-se como um instrumento político de manutenção e expansão do latifúndio, hoje entendido pelo sinônimo de agronegócio.

Com a intensificação do movimento da luta pela terra na fronteira amazônica, tem-se, concomitantemente, o aumento dos números de mortes no campo, principalmente de camponeses e de pessoas engajadas na luta. O Estado do Pará vem se tornando um dos epicentros de casos de assassinatos no campo, característica que se mantém até os dias atuais, como é demonstrado nos quadros 05 e 06.

Quadro 05 - Assassinatos no campo no Estado do Pará entre 1964 e 1996

\begin{tabular}{|c|c|c|c|}
\hline Ano & Número de mortes & Ano & Número de mortes \\
\hline 1964 & 04 & 1981 & 19 \\
\hline 1965 & 03 & 1982 & 24 \\
\hline 1966 & 00 & 1983 & 38 \\
\hline 1967 & 03 & 1984 & 115 \\
\hline 1968 & 01 & 1985 & 92 \\
\hline 1969 & 04 & 1986 & 49 \\
\hline 1970 & 01 & 1987 & 34 \\
\hline 1971 & 02 & 1988 & 15 \\
\hline 1972 & 03 & 1989 & 21 \\
\hline 1973 & 13 & 1990 & 15 \\
\hline 1974 & 10 & 1991 & 12 \\
\hline 1975 & 06 & 1992 & 22 \\
\hline 1976 & 08 & 1993 & 12 \\
\hline 1977 & 05 & 1994 & 13 \\
\hline 1978 & 09 & 1995 & 38 \\
\hline 1979 & 17 & 1996 & 667 \\
\hline 1980 & 39 & Total & \\
\hline
\end{tabular}

Fonte: Acervo arquivístico da CPT/Xinguara

No quadro 05, observa-se o número de mortes no Estado do Pará no período de repressão militar no Brasil, entre 1964 e 1985, e o período de abertura democrática até 1996, para o qual os anos de início dessa transição democrática, em 1985 e 1986, foram os momentos em que ocorreu o maior número de mortes no campo paraense, contabilizando 115 e 92 assassinatos, respectivamente.

O período de 1984 a 1986, [...] representa, já durante a chamada “Nova República”, a ampliação do número de assassinatos no campo. Em dois anos, 85 e 86, foram mortos, nada mais nada menos, do que 524 trabalhadores. Este acirramento dos confrontos armados no campo está em conexão direta com o processo desencadeado pela elaboração e início da implementação do Plano Nacional de Reforma Agrária pelo Governo Federal. Outra razão importante foi o surgimento da UDR - União Democrática Ruralista, liderada pelo latifundiário Ronaldo Caiado, que passou a fazer a defesa intransigente dos latifundiários deste país. Denúncias de participação da UDR nos processos de expulsão e morte de trabalhadores no campo passaram 
a ser constantes. Sua ação ampliou-se por todo o país. Em 84 e 85 várias regiões concentram conflitos, especialmente a região do Bico do Papagaio, que junto com as regiões sudeste do Pará, Bragantina e Pindaré-Mearim, no Maranhão, formam a principal área com registro de assassinatos no campo. (OLIVEIRA, 1988, p. 46-47).

Em Oliveira (1988), observamos as conexões políticas que desencadearam o aumento do número de assassinatos no campo brasileiro e, de forma particular, na fronteira amazônica, no período da abertura democrática do país, configurando a possibilidade efetiva da reforma agrária em um motivo de retaliação das forças dominantes no espaço agrário. A contextualização de Oliveira (1988) corrobora para entendermos o ápice dos assassinatos no Pará nos anos de 1985 e 1986, visto no quadro 05, em que nordeste, sul e sudeste do Estado foram as regiões com maior conflito por terra e, consequentemente, com maior número de mortes.

Os dados apresentados pela Comissão Pastoral da Terra, a partir de 1997, demonstram que os conflitos agrários e o número de mortes no campo não foram algo específico dos anos do ambiente repressivo pelo qual o Brasil passou, mas, por conseguinte, esses números de violência e assassinatos no campo continuaram constantes, mantendo-se até os dias atuais.

Quadro 06 - Assassinatos no campo no Brasil entre 1997 e 2019

\begin{tabular}{|c|c|c|c|c|c|c|c|}
\hline Ano & Brasil & Pará & Sul e sudeste do Pará & Ano & Brasil & Pará & Sul e sudeste do Pará \\
\hline 1997 & 30 & 12 & 09 & 2009 & 25 & 08 & 06 \\
\hline 1998 & 47 & 12 & 10 & 2010 & 34 & 18 & 09 \\
\hline 1999 & 27 & 09 & 08 & 2011 & 29 & 12 & 07 \\
\hline 2000 & 21 & 05 & 05 & 2012 & 36 & 06 & 00 \\
\hline 2001 & 29 & 08 & 06 & 2013 & 34 & 06 & 05 \\
\hline 2002 & 43 & 20 & 14 & 2014 & 36 & 09 & 08 \\
\hline 2003 & 73 & 33 & 26 & 2015 & 50 & 19 & 10 \\
\hline 2004 & 39 & 15 & 10 & 2016 & 61 & 06 & 03 \\
\hline 2005 & 38 & 16 & 11 & 2017 & 71 & 22 & 16 \\
\hline 2006 & 39 & 24 & 14 & 2018 & 28 & 16 & 04 \\
\hline 2007 & 28 & 05 & 03 & 2019 & 32 & 12 & 03 \\
\hline 2008 & 28 & 13 & 12 & Total & 878 & 306 & 199 \\
\hline
\end{tabular}

Fonte: CPT Nacional - Massacres no campo

Os números de assassinatos no campo brasileiro, entre 1997 a 2019, foi igual aos constantes números das décadas anteriores, revelando a permanência dos conflitos do campo, em que 2003 e 2016-2017 foram anos de maior número de mortes. Desse período, o Estado do Pará concentrou $34,85 \%$, das 878 mortes ocorridas no país, e somente o sul e o sudeste paraense contabilizaram $65,03 \%$, dos 306 casos de assassinatos no Estado, ou seja, 22,66\% em relação ao Brasil.

Esses dados demonstram a centralidade que o sul e sudeste do Pará ganham no cenário agrário brasileiro, caracterizando-se enquanto regiões de maior conflito do país. Entende-se com isso que o espaço agrário dessa parte do Pará é formado por uma geografia na qual as diferentes formas de violência - física, moral, simbólica, psicológica, morte - têm sido praticadas como uma forma de conter do conflito social, configurando-se enquanto uma ação material da expansão do modo capitalista de produção no campo e, em contrapartida, das formas de resistências que são engendradas contra a homogeneização do capitalismo no espaço agrário.

A partir dos intensos conflitos agrários na fronteira amazônica, observa-se um rastro de violência que acompanha a formação territorial da região, como se a política direcionada para o desenvolvimento da Amazônia fosse pautada pela morte. A alteridade que caracteriza a fronteira (MARTINS, 2009) define-se pela destruição do outro, anulando as possibilidades de existência do lado mais vulnerável nesse campo em disputa, daí resultam-se as ordens de despejos dos posseiros, acompanhadas por uma política da morte, a necropolítica (MBEMBE, 2018). 
Entende-se que na fronteira há uma definição da vida como implantação e manifestação de uma relação de poder, a qual exerce capacidade política de decisão sobre quem vive e quem morre (MBEMBE, 2018). Desse modo, impõem-se a morte para quem enfrenta a ação das relações capitalistas de produção no espaço agrário a expropriação da terra e da vida.

A vida enquanto comércio torna-se, a partir de pesquisa feita no acervo da CPT, uma realidade. Ao passo que a morte de camponeses, religiosos, advogados, lideranças sindicais e políticas passam a receber valores diferenciados, dependendo do alcance de suas atuações e do engajamento na luta pela terra e pela vida.

O horror experimentado sob a visão da morte se transforma em satisfação quando ela ocorre com o outro. É a morte do outro, sua presença física como um cadáver, que faz o sobrevivente se sentir único. E cada inimigo morto faz aumentar o sentimento de segurança do sobrevivente (MBEMBE, 2018, p. 62)

O sentimento de segurança do fazendeiro, grileiro ou empresário é gerado pela morte das pessoas que se opõem à lógica da terra enquanto um negócio. Tem sido assim o percurso da implantação de grande parte dos latifúndios especulativos e grilados na fronteira amazônica. 0 assassinato de camponeses, religiosos, agentes da Pastoral da Terra, sindicalistas, advogados e parlamentares não é apenas uma retaliação à luta pela terra, mas também um mecanismo de silenciar e enfraquecer o movimento, para o qual a morte de integrantes force a intimidação dos demais, levando à desarticulação e à desistência da luta. Contudo, em vez de frear a organização e o poder de enfretamento dos camponeses e dos movimentos sociais e entidades políticas, essa situação tem aguçado ainda mais a resistência, ensejando estratégias de enfrentamento para a conquista da terra e a reprodução social familiar no campo.

Os conflitos agrários na fronteira amazônica reproduziram e reproduzem no espaço uma geografia da morte, o que demonstra a complexidade agrária regional em tempos de desenvolvimento.

Quadro 07 - Casos de assassinatos no sul do Pará

Rio Maria, 10 de junho de 1991

\section{Casos de Assassinatos}

A região do sul do Pará é reconhecida pela violência e pelos assassinatos cometidos contra lavradores e contra os que os apoiam. Há um aspecto que cabe ressaltar. As mortes são desferidas contra alvos selecionados, atingindo de forma especial a Organização do Trabalho. Lideranças sindicais e políticas têm sido ameaçadas e, de fato, perdido a vida. Há um recrudescimento impressionante a partir de 23 de abril deste ano, apesar de toda a repercussão nacional e internacional que houve com a morte de Expedido Ribeiro de Souza. Vejamos:

C. 1. O posseiro Raimundo Sousa Neto foi assassinado na fazenda Diadema, [...], no dia 23 de abril.

C.2. O posseiro Manoel Ribeiro dos Santos foi assassinado na fazenda Novo Mundo, [...], no dia 29 de abril. Nesse mesmo dia pistoleiros sequestraram Raimundo Honorato dos Santos, 60 anos, sua neta Aparecida Ribeiro dos Santos, 8 anos, e o adolescentes de 14 anos, Antônio Ribeiro dos Santos. Até hoje não se tem notícias sobre eles. É possível que estejam mortos.

C.3. O lavrador Berto Pereira Costa foi assassinado na fazenda CETENCO, em Santana do Araguaia, no dia 9 de maio.

C.4. Um posseiro foi assassinado na fazenda Nazaré, [...], no município de Parauapebas, provavelmente em 16 de maio

C.5. Um desconhecido, possivelmente pistoleiro, foi morto em Rio Maria, depois de ameaçar o sindicalista Valdério, em 13 de maio. 
Os casos de assassinatos apresentados no quadro 07, ocorridos em 1991, demostram algumas das situações de violência com mortes que se encontram documentados no acervo arquivístico da CPT-Xinguara. Para além das mortes, deparou-se com listas de pessoas (testemunhas e parentes) que foram ameaçadas, passando a viver sob constate tensão.

O conflito e a violência não terminam com a morte da pessoa que lidera o movimento, seja militante, político, religioso, seja um camponês. A tensão continua, havendo uma constante pressão psicológica na tentativa de silenciar os que ficaram vivos e, assim, frear a luta pela terra e ao mesmo tempo deixar impunes os mandantes e os assassinos. Essa psicologia do medo, por outro lado, reforça a luta não somente pela terra, mas também, para que seja feita justiça para com as pessoas mortas e seus familiares.

Destaca-se, por exemplo, o conflito da Fazenda Novo Mundo, em Xinguara, onde posseiros foram assassinados por pistoleiros. Os respectivos assassinos foram capturados pela população local e levados à polícia. O mandante do crime também foi acusado de contratar pistoleiros para reforçar o contingente policial que despejou as famílias da terra, os quais são acusados de terem queimado as barracas e destruído plantações dos camponeses.

Sendo assim, observa-se nesse e em outros casos já relatados aqui, a ação da pistolagem enquanto um fenômeno miliciano ocorrido na Amazônia, no qual o pistoleiro atua como mediador entre quem manda matar e quem é morto.

\begin{abstract}
A pistolagem, fenômeno que começou também a integrar o cotidiano de ocupação da terra, é algo recente na Amazônia, datando de mais ou menos trinta anos. Mas, não só neste aspecto o pistoleiro da Amazônia difere do cangaceiro e do capanga do nordeste. Ele tem uma origem histórica e social diferente da deles e possui uma natureza também própria. O pistoleiro surge na região para proteger contra invasão (por parte de posseiros) as grandes extensões de terras adquiridas mas ociosas ou improdutivas. Um pistoleiro pode ser contratado para expulsar colonos que as ocuparam; para assassinar lideranças e sindicalistas. Ou ainda, para "ajudar" nas ações policiais de despejo de posseiros. Como o contingente policial era, e ainda é insuficiente para cumprir ordens de mandado emanadas da Justiça, alguns fazendeiros inseriam pistoleiros nos contingentes policiais encarregados da expulsão (LOUREIRO; PINTO, 2005, p. 83)
\end{abstract}

Essa ação de pistolagem apresentada por Loureiro e Pinto (2005), em muitas situações de violência e expropriação no campo, esconde os verdadeiros mandantes dos crimes de assassinatos que, como demonstram alguns processos de conflitos do acervo Frei Henri de Roziers, continuam, muitos deles, sem desfecho, produzindo uma judicialização da impunidade.

No referido acervo, encontramos vários conflitos envolvendo denúncias de sindicalistas, políticos e advogados sobre a ação criminosa de pistoleiros no assassinato de trabalhadores rurais e na expropriação/despejo de famílias posseiras de suas terras por grupos de grileiros que tomam as propriedades, a fim de explorar madeiras e terra. Dentre os casos de conflitos, em muitos deles não houve a punição dos criminosos envolvidos, algo corriqueiro nos municípios paraenses, como exposto na citação a seguir:

Nos últimos 33 anos, houve 772 assassinatos no campo no Pará, com a realização de apenas três julgamentos de mandantes dos crimes: o caso exemplar do líder rural e poeta Expedito Ribeiro, cujo condenado, Jerônimo Alves de Amorim, cumpre, lamentavelmente, a sentença em prisão domiciliar em sua confortável residência em Goiânia; no caso do assassinato de João Canuto (que teve também dois familiares igualmente assassinados), mesmo condenados, os mandantes do crime há dois anos recorrem da sentença em liberdade, de forma que o processo permanece no Tribunal de Justiça do Estado aguardando solução; no caso de Eldorado de Carajás os dois comandantes da operação policial foram condenados, Coronel 
Pantoja e o Major Oliveira, estando presos em cela especial de um presídio militar (LOUREIRO; PINTO, 2005, p. 88).

A partir de Loureiro e Pinto (2005), observa-se pequeno, para não dizer insignificante, o número de casos de assassinatos que foram a julgamento diante do número de pessoas (posseiros, religiosos, advogados, sindicalistas, entre outros) que foram mortas no campo até 2005. Isso demonstra a morosidade na apuração dos casos, os quais prolongam-se durante anos, resultando em situações como a não punição dos assassinos e dos mandates.

Mesmo os crimes que foram a julgamento, tal feito só se concretizou depois de longos anos de lutas, pressão e denúncias de entidades nacionais e internacionais ligadas aos direitos humanos. A lentidão do judiciário evidencia as influências que o poder político e econômico exerce nas comarcas do interior e da capital paraense para o retardamento dos processos e dos julgamentos (LOUREIRO; PINTO, 2005).

\begin{abstract}
Processos exemplares que apuram o assassinato de lideranças e chacinas de trabalhadores rurais permanecem em comarcas do interior, sem qualquer previsão dos acusados irem a júri, tais como: o assassinato do advogado Gabriel Pimenta, em Marabá - 24 anos; a chacina de oito trabalhadores na Fazenda Ubá, em São João do Araguaia - vinte anos; a chacina de cinco trabalhadores na Fazenda Princesa, em Marabá - dezenove anos; o assassinato do sindicalista Braz, no Rio Maria - quinze anos; o assassinato do sindicalista Arnaldo Delcídio, em Eldorado de Carajás - doze anos; o assassinato de Onalício Barros e Valentim Serra em Parauapebas sete anos. Se o Tribunal de Justiça do Pará promete levar o caso da freira Dorothy Stang a júri em seis meses, como explicar a lentidão ou o abandono de outros casos exemplares? Acrescente-se ainda que no processo do assassinato de Expedito Ribeiro, três juízes abandonaram o caso e se negaram a presidir o júri e que, também no caso Eldorado do Carajás, juízes da capital designados para o caso negaram-se a presidir o julgamento, alegando "razão de foro íntimo" (LOUREIRO; PINTO, 2005, p. 88-9).
\end{abstract}

$\mathrm{Na}$ assertiva de Loureiro e Pinto (2005), percebe-se a complexidade da questão agrária na fronteira amazônica, chegando à situação em que juízes desistissem de presidir o julgamento de alguns casos, como o do sindicalista Expedito Ribeiro. A repercussão internacional do assassinato da missionaria estadunidense Dorothy Stang apressou o julgamento dos criminosos do caso, contudo, não conseguiu ampliar os holofotes sobre os demais crimes que continuam com os assassinos e mandantes impunes.

A impunidade tem sido marca da luta pela terra na fronteira amazônica, caracterizando-se como segunda forma de violência contra as pessoas que foram assassinadas, não havendo, portanto, justiça pelos crimes. A impunidade dos criminosos impulsiona, de certa forma, a continuação das ações de violência no campo, haja vista, que ao cometer o delito e não ser punido, os mandantes e assassinos têm a garantia que continuarão em liberdade após seus crimes.

Assim, destaca-se que o conflito, a violência e a morte têm sido os estigmas da trajetória camponesa na fronteira amazônica. As conquistas sociais dos assentamentos rurais que hoje existem na região são resultado de muito sangue derramado nos fronts de luta, e isso foi o que tentamos delinear nesse artigo enquanto cicatrizes da luta pela terra.

\title{
Considerações finais
}

A geografia dos conflitos agrários na fronteira amazônica é grafada no espaço por meio de violência e mortes que têm marcado a trajetória camponesa nessa parte do Brasil. A própria conquista dos assentamentos rurais tem sido efetivada por meio da luta, do derramamento de 
sangue e da persistência dos camponeses nos fronts de batalha contra as cercas dos latifúndios especulativos e de grileiros.

A expansão das propriedades capitalistas na Amazônia, a partir de 1950, desencadeou, concomitantemente, a luta pela terra dos posseiros que, expropriados, travaram uma luta pelo trabalho livre e autônomo e pela terra liberta. Mas a luta camponesa não se ateve somente à terra e ao trabalho, mas também à vida, precisando, portanto, criar estratégias para fugir das balas dos pistoleiros - encomendadores da morte no campo.

Os assassinatos e massacres no espaço agrário têm ocorrido de forma incessante durante os últimos 70 anos na fronteira amazônica. São camponeses, religiosos, sindicalistas, advogados e lideranças que perdem a vida em função de uma política direcionada à morte. Em muitos casos, os assassinos e mandantes não foram sequer julgados, o que demonstra, também, uma política da impunidade.

Observa-se nos casos de conflitos agrários no acervo da CPT que a grilagem é fator predominante nos conflitos por terra, além de forma ilegal de apropriação por um fazendeiro ou empresário, gerando a expropriação de posseiros que entram na luta pelo reconhecimento de suas terras já ocupadas, muitas vezes, por mais de uma geração.

A violência é sentida pelos posseiros frente às ordens de despejos da terra, à destruição da casa e dos roçados, à perda nas relações de vizinhança, à pressão psicológica sobre a perda da vida, à humilhação moral, aos atos de torturas, junto ao cárcere e à morte de familiares e amigos.

Os dados dos conflitos no campo apresentados pela CPT nos últimos anos demonstram que as lutas sociais no campo não estão atreladas somente à terra, mas também a questões relacionadas à água, à floresta e aos territórios étnicos e extrativistas. A ampliação das lutas sociais no campo reflete o movimento de fronteira cada vez mais para dentro da Amazônia, interrompendo percursos de rios, queimando a mata, desterritorializando as populações tradicionais. Por outro lado, a resistência tem sido a ação do existir dessas populações agrárias e extrativistas, que adentram na luta para manter vivas suas tradições, crenças e a esperança de fazer da terra a morada e a vida. 


\section{Referências}

CPTNACIONAL-MASSACRES NO CAMPO. https://www.cptnacional.org.br/ noticias/acervo/massacres-no-campo/110-para/3972-eldorado-dos-carajas-17-04-1996. Acesso em 31 de março de 2020.

Conflitos no Campo - Brasil 2019. Goiânia: CPT Nacional - Brasil, 2020.

HÉBETTE, J. (2004). O grande Carajás: um novo momento da história moderna da Amazônia paraense. In: HÉBETTE, J. (Org.). Cruzando a fronteira: 30 anos de estudo do campesinato na Amazônia. Belém: EDUFPA, p. 31-55.

HEREDIA, B. M. A. (1979). A morada da vida: o trabalho familiar de pequenos produtores do nordeste do Brasil. Rio de janeiro: Paz e Terra.

LOUREIRO, V. R. (2004). Amazônia: Estado-Homem-Natureza. $2^{\circ}$ Ed. Belém: Cejup.

LOUREIRO, V. R.; PINTO, J. N. A. (2005). A questão fundiária na Amazônia. Estudos Avançados, n. 19 (54).

MARTINS, J. S. (2009). Fronteira: a degradação do Outro nos confins do humano. São Paulo: Contexto. MARTINS, J. S. (1980). Expropriação e violência: a questão política no campo. São Paulo: Editora Hucitec.

MBEMBE, A. (2018). Necropolítica: biopoder, soberania, estado de exceção, política da morte. Traduzido por Renata Santini. São Paulo: n-1 edições.

MEDEIROS, L. S. (1996). Dimensões políticas da violência no campo. Tempo. Revista do Departamento de História da UFF, Rio de Janeiro, v. 1, n.1, p. 126-141.

MONTENEGRO, J. (2010). Conflito pela terra e pelo território: ampliando o debate sobrea questão agrária na América Latina. In. SAQUET, M. A.; SANTOS, R. A. (Orgs). Geografia agrária, território e desenvolvimento. $1^{\text {a }}$ ed. São Paulo: Expressão Popular.

OLIVEIRA, A. U. (1988). A geografia dos conflitos no campo. São Paulo: Contexto; Edusp.

PORTO-GONÇALVES, C. W. (2004). Violência e democracia: o que dizem os dados de 2003. Conflitos no Campo Brasil, Goiânia, p. 09-26.

QUIJANO, A. (2005). Colonialidade do Poder, eurocentrismo e América Latina. In.: A colonialidade do saber: eurocentrismo e ciências sociais. Perspectivas latino-americanas. Buenos Aires: CLACSO, Consejo Latinoamericano de Ciencias Sociales. 